\title{
The effect of multicolor playground markings on children's physical activity level during recess
}

\author{
Gareth Stratton Ph.D. ${ }^{\mathrm{a}, *}$, Elaine Mullan ${ }^{\mathrm{b}}$ \\ ${ }^{\text {a }}$ REACH Group, Research Institute for Sport and Exercise Sciences, Liverpool John Moores University, $15-21$ Webster St., Liverpool L3 2ET, UK \\ ${ }^{\mathrm{b}}$ Health Promotion Division, National Assembly for Wales, UK
}

Available online 31 August 2005

\begin{abstract}
Background. British children do not meet daily physical activity recommendations, and as yet no sustainable intervention has been reported to address their sedentary lifestyle. The purpose of this investigation was twofold: First, to examine whether painting playgrounds with multicolored markings would increase the percent of recess time spent in moderate to vigorous physical activity (MVPA) and vigorous physical activity (VPA) in girls and boys and second to quantify the contribution recess makes to national recommendations for young people's physical activity.

Methods. MVPA and vigorous physical activity (VPA) were measured using short wave heart rate telemetry. Physical activity levels were compared before and after playgrounds were painted in 4 intervention schools and compared to 4 matched schools with unmarked playgrounds. Schools were situated in areas of deprivation. Ninety-nine children completed the study.

Results. A significant interaction (group $\times$ time) was evident for MVPA and VPA. Time spent in MVPA and VPA increased significantly in intervention schools as a result of playground painting. Boys were more active than girls, and activity decreased with age, but neither difference reached significance.

Conclusion. Multicolor playground markings can be a low-cost method of increasing children's daily physical activity levels in the short term. If these increases were sustained, then school playgrounds with multicolor markings would make a valuable contribution to physical activity recommendations for young people.
\end{abstract}

(C) 2005 Elsevier Inc. All rights reserved.

Keywords: Schools; Children; Recess; Physical activity; Multicolor markings

\section{Introduction}

British children now take part in less physical activity at school than almost all of their European counterparts (Armstrong and McManus, 1994). Furthermore, concern has been expressed that levels of physical activity among young people have declined to the stage where they may be detrimental to their current health and well-being as well as that of the future population (Centers for Disease Control and Prevention, 1997; Biddle et al., 1988). Children's physical inactivity has been categorized as a modifiable risk factor for lifestyle-related diseases such as osteoporosis (Bailey, 1994) and coronary heart disease (Andersen et al., 2004). Sixty minutes per day of MVPA has been recommended as the optimal, and $30 \mathrm{~min}$ as the minimal level for 5- to 18-year-olds (Centers for Disease

\footnotetext{
* Corresponding author. Fax: +44 1512314334.

E-mail address: g.stratton@livjm.ac.uk (G. Stratton).
}

Control and Prevention, 1997; Biddle et al., 1988). Unfortunately, 6- to 7-year-old British school children continually fail to meet the optimal criterion (Welsman and Armstrong, 1997). Schools have long been recognized as key settings to promote physical activity recommendations (Centers for Disease Control and Prevention, 1997; Biddle et al., 1988; Iverson et al., 1985).

Children are more likely to engage in MVPA in unstructured play where they are free to interact with their play area and their peers (Pate et al., 1996). In Britain, primary age children experience up to 600 recess periods per year, 3 times a day, 5 days per week, 39 weeks per year. However, few investigators have succeeded in implementing sustainable interventions aimed at increasing children's participation in physically active behavior during play (McKenzie et al., 1997). Welk (1999) suggested that factors that "enable" children to be physically active, such as playground markings, prompts from teachers, or support from parents, are key to health promotion in young people. 
Two studies (Health Promotion Wales, 1997; Stratton, 2000), have measured the effects of painting playgrounds on children's physical activity during school recess. Even though both projects reported increases in the use of the markings and physical activity levels, studies were limited by the omission of a control group or failing to adequately quantify MVPA before or after the intervention.

There is a need for research to examine how children's physical activity during school playtime can contribute toward the MVPA recommendation. Ridgers et al. (2006) recently hypothesized that $40 \%$ of available daily recess time (equivalent to about $34 \mathrm{~min}$ ) should represent a physical activity promotion target for schools yet guidelines of physical education lessons suggest that children should be active for $50 \%$ of lesson time (Centers for Disease Control and Prevention, 1997). Furthermore, physical activity guidelines recommend that children engage in VPA to promote musculo-skeletal strength and bone health (Biddle et al., 1988). There is also no current consensus on a physical activity target for school recess time.

The purpose of this investigation was twofold: First, to examine whether painting playgrounds with multicolored markings would increase the percent of recess time spent in MVPA and VPA in girls and boys and second to quantify the contribution recess makes to national recommendations for young people's physical activity.

\section{Methods}

\section{Sample and settings}

Eight schools took part in the study. Two early primary (4-7 years) and two late primary schools ( $7-11$ years) from areas of deprivation in Northeast Wales took part in the intervention; two late primary and two early primary schools from Northwest England served as their controls. The schools from Northeast Wales were among 67 who received a Health Promotion Wales, charity grant of $£ 800$ to paint their playground with multicolor markings. The schools in the Northwest of England were matched to the schools in Northeast Wales by playground dimension and socio-economic status (Jarman, 1984). Geographically, schools in the Northeast of Wales were within 40 miles of the schools in the Northwest of England and had a similar climate. Curriculum in schools in both areas was similar and the distance between control and intervention schools minimized the potential for communication between children and teachers.

Fifteen girls and 15 boys (5 from each age group) from each school (intervention and control) were randomly selected for participation in the study. None of the schools had existing playground markings and while not identical, all their outdoor areas had large tarmac and grassed areas for play. The playgrounds of the intervention schools were painted during the summer vacation. Playgrounds were painted in bright fluorescent colors that varied according to school preference, although castles, dragons, clock faces, mazes, fun trails, dens, hopscotch, letter squares, snakes and ladders, and various animals were consistently popular in early primary schools. Late primary schools included markings for netball, football, and short tennis, and targets for games related skills. Control schools had no playground markings. Small pieces of sports equipment such as skipping ropes and footballs were prevalent in all school playgrounds. Of the initial 120 children, complete data sets for 51 boys (25 early primary, 26 late primary) and 48 girls (29 early primary, 19 late primary) were available for further analysis. Full data sets were obtained for 17 early primary and 18 late primary boys, and 19 early primary and 13 late primary girls in intervention schools and 8 early primary and 8 late primary boys, and 10 early primary and 6 late primary girls in control schools. Data sets were lost primarily due to missing heart rate data and incomplete heart rate time curves.
Each school playground employed 2 supervisors, who were not informed of the aims of the investigation, neither were they trained in promoting physically active behavior

\section{Instruments and procedure}

Baseline data were collected for 4 weeks in June, immediately prior to playgrounds being painted. After playgrounds were painted, data were collected for 4 continuous weeks through September and October in intervention and control schools. Data were only collected from safe and dry playgrounds. Schoolteachers were asked to restrict children's opportunity to play on grass during the study. All children and parents gave written informed consent to participate in the investigation.

Body mass and stature were measured before and during the intervention phase using standard techniques (Lohman et al., 1991). Sportstester heart rate telemeters (Electro-Polar, Kempele, Finland) were used to assess children's heart rate and play duration during recess. Prior to playtime, children's supine resting heart rates were recorded minute by minute for $15 \mathrm{~min}$ at least $2 \mathrm{~h}$ postprandial in a quiet, dark room at school. The three lowest consecutive heart rates were used as baseline. Telemeters started recording just prior to the children entering the playground and stopped when children came in from the playground.

Using 200 beats $\mathrm{min}^{-1}$ as maximum heart rate, heart rate reserve (HRR) at 50 and $75 \%$ thresholds was calculated for each individual to represent moderate to vigorous (MVPA) and vigorous physical activity (VPA), respectively (Stratton, 1996). The percentage of playtime spent in MVPA was calculated as the total amount of time spent above this threshold. VPA was included within the MVPA time but was also reported separately. Measurements took place during one morning, lunch, and afternoon play period, on 3 separate days during the same week (Durant et al., 1992). On average, schools allocated 15 min to morning and afternoon break and an hour for lunch.

\section{Statistical analysis}

Descriptive statistics were computed for all anthropometric and physical activity parameters, and grouped according to sex (girl, boy), group (control, intervention), age (early primary, late primary), and time (before, after). There were no significant differences reported between control and intervention groups prior to the intervention. As the amount of time given to playtime in each school varied, and as body mass increased with age, both play duration and body mass were used as covariates. To maintain statistical power, three $2 \times 2$ ANCOVAs (sex $\times$ time; group $\times$ time; age $\times$ time) were used to detect main effects and interactions for MVPA and VPA. There was no interaction using school as an independent variable allowing all schools to be categorized by group. SPSS 10.1 was used to analyze the data and alpha level was set at $P<.05$.

\section{Results}

Descriptive data for mass stature and play duration (mean duration of 3 playtimes) are reported in Table 1. Late primary age children were significantly taller, $F_{1,208}=115.5$, and heavier, $F_{1,208}=408.7$, than their early primary counterparts. There were no significant differences in body mass or stature between girls and boys, or control and intervention groups, before or after the intervention. Descriptive statistics for MVPA and VPA data, before and after the intervention, are reported in Figs. 1 and 2.

\section{Daily physical activity levels in recess}

Fig. 1 shows that MVPA in the intervention group increased from $36.7 \%( \pm 23.9)$ to $50.3 \%( \pm 28.9)$ of playtime compared to a decrease from $39.9( \pm 21.1)$ to $33.4( \pm 18.4)$ in the control group 
resulting in a significant interaction $\left[F_{1,204}=13.7 ; P<.01\right]$. There were no significant main effects. Early primary school children increased their MVPA from $40.9 \%( \pm 19.5)$ to $43.3 \%$ $( \pm 23.8)$ and late primary from $33.5 \%( \pm 26.7)$ to $40.4 \%( \pm 30.1)$ as a result of the intervention. Boys increased their MVPA from $40.6 \%( \pm 23.3)$ to $44.8 \%( \pm 26.6)$ and girls from $35.2 \%( \pm 21.9)$ to $39.8 \%( \pm 25.1)$ before and after the intervention, respectively. There were no significant age by time or sex by time interactions.

Fig. 2 illustrates that VPA increased from $7.9( \pm 10.9)$ to 12.4 $( \pm 15.8) \%$ in the intervention group compared to $8.0( \pm 10.1)$ and $8.0( \pm 10.9)$ before and after the intervention, respectively; again, this interaction was significant $\left[F_{1,204}=4.05 ; P<.03\right]$. Early primary age children increased their VPA from $7.5( \pm 8.7)$ to $9.1 \%( \pm 10.9)$ and late primary from $8.8( \pm 13.1)$ to $12.9 \%$ $( \pm 18.3)$ of playtime before and after the intervention, respectively. Boys increased their VPA from $9.8( \pm 11.9)$ to 12.6 $( \pm 15.5)$ and girls from $5.9( \pm 8.4)$ to $7.9( \pm 11.4) \%$ of recess before and after the intervention, respectively, VPA data. There were no significant age by time or sex by time interactions for VPA.

\section{Discussion}

The primary aim of this investigation was to assess changes in primary school children's MVPA and VPA, before and after their school playgrounds were painted with multicolored markings. The secondary aim was to quantify the contribution recess makes to national recommendations for young people's physical activity (Ridgers et al., 2006).

MVPA significantly increased as a result of playground marking. This was particularly encouraging given that the data were adjusted both for play duration, which decreased during the intervention in late primary school playgrounds, and body mass, which is negatively related to running performance (Cureton et al., 1991). In concurrence with the literature, boys were more active than girls, though not significantly so (Welsman and Armstrong, 1997; Pate et al., 1996; Stratton, 1999a; Sleap and Warburton, 1992). It is noteworthy that the increase in MVPA in late primary school children was more than double that found in early primary children although a reduction in MVPA in the control schools was not apparent in the intervention schools.

An additional aim of this study was to assess whether children met the proposed $50 \%$ of playtime in MVPA criterion.
Prior to the intervention, children in both intervention and control groups were over $10 \%$ short of this criterion. After the intervention, MVPA in the intervention group exceeded 50\% of recess time, whereas the control group suffered a decrease in activity. This decrease may have been a result of seasonal or random variations in physical activity during recess that has previously been reported in the literature (Stratton, 1999a). The increase in activity in the intervention group was an encouraging finding, as MVPA exceeded values reported in similar studies in early (Ridgers et al., 2006) and late (Stratton, 1999a) primary age children. Nevertheless, children in this study did not reach the $60 \%$ of MVPA reported in other investigations (Kraft, 1989; Payne and Morrow, 1993) although it is difficult to directly compare the results to those of Hovell et al. (1978) and Kraft (1989) who used systematic observation to quantify levels of physical activity and the data were collected more than 20 and 10 years ago, respectively. In contemporary times the $50 \%$ threshold may present an achievable goal and could provide a useful health-promoting target for schools. Out of 601 child playtimes assessed, 86 (46 intervention, 40 control) exceeded the $50 \%$ MVPA threshold before the playgrounds were painted compared to 101 (78 intervention, 23 control) after. If a lower threshold of $40 \%$ MVPA proposed by Ridgers et al. (2006) was used, 134 (71 intervention, 63 control) playtimes recorded met this threshold before playground painting compared to 151 (101 intervention, 50 control) after. These thresholds represent realistic health promotion targets for primary schools to adopt.

VPA represents an intensity of exercise that may stimulate increases in cardiorespiratory fitness in this age group (Payne and Morrow, 1993). Results suggest that the intervention was associated with an increase in VPA compared to no change in the control group. Various markings such as hopscotch and clock face required children to participate in games that were of high intensity and short duration. The results also concur with other findings that boys engage in greater amounts of higher intensity activity than girls (McKenzie et al., 1997; Stratton, 1999a).

Overall, results suggest that school playgrounds offer a sustainable context for promoting VPA. After failing to increase VPA through a home-based physical activity intervention, Saakslahti et al. (1999) proposed that sports clubs and school physical education lessons were contexts where VPA could be promoted, and evidence from this study

Table 1

Descriptive data for late primary and early primary boys and girls (in italics), intervention and control groups, before and after playgrounds were painted

\begin{tabular}{|c|c|c|c|c|c|c|c|c|}
\hline & \multicolumn{4}{|l|}{ Early primary } & \multicolumn{4}{|l|}{ Late primary } \\
\hline & \multicolumn{2}{|l|}{ Control } & \multicolumn{2}{|l|}{ Intervention } & \multicolumn{2}{|l|}{ Control } & \multicolumn{2}{|l|}{ Intervention } \\
\hline & Before (SD) & After (SD) & Before (SD) & After (SD) & Before (SD) & After (SD) & Before (SD) & After (SD) \\
\hline & $1.2(.07)$ & $1.22(.07)$ & $1.18(.07)$ & $1.18(.07)$ & $1.4(.05)$ & $1.42(.05)$ & $1.36(.08)$ & $1.4(.11)$ \\
\hline \multirow[t]{2}{*}{ Body mass (kg) } & $22(3.4)$ & $23(3.5)$ & $23(4.4)$ & $23.4(4.2)$ & $33.7(5.1)$ & $34.5(4.9)$ & $33.9(9.0)$ & $37.1(9.8)$ \\
\hline & $23.9(4.8)$ & $23.5(6.0)$ & $23.5(3.7)$ & 23.7 (4.8) & $38.4(8.5)$ & $40(9.0)$ & $34.6(6.4)$ & $36.3(7.5)$ \\
\hline
\end{tabular}




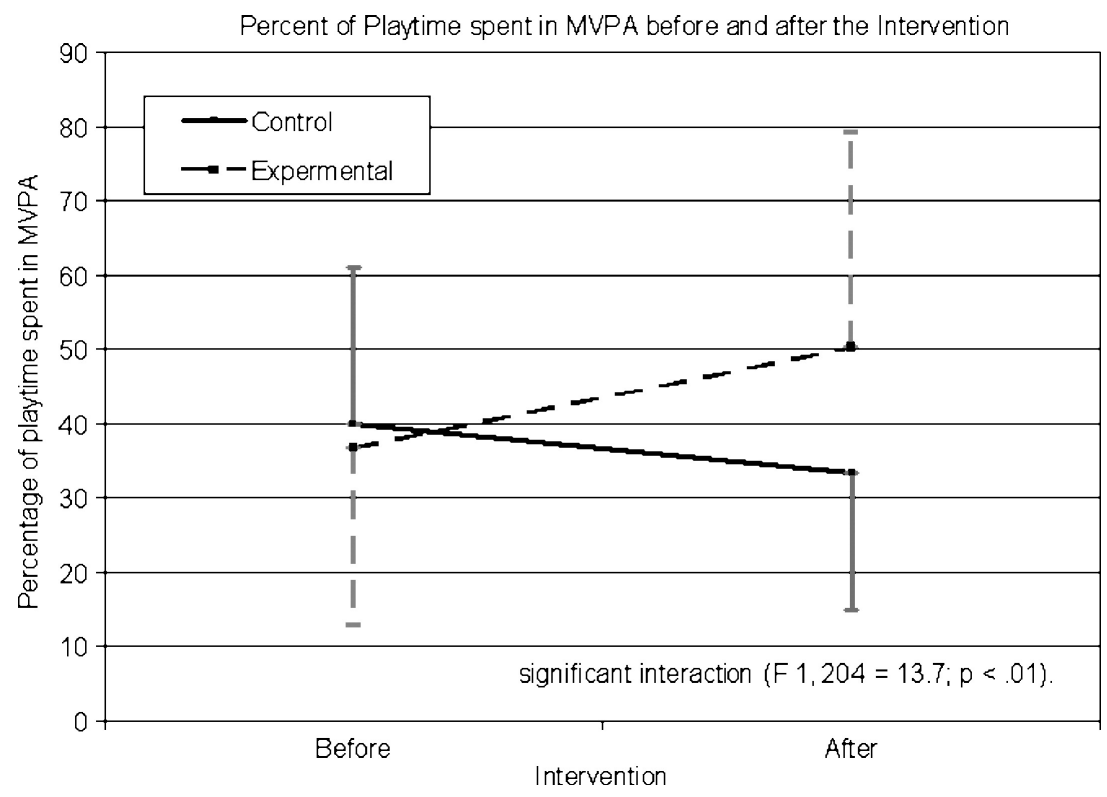

Fig. 1. Control and intervention group's MVPA before and after playgrounds were painted.

suggests that primary school playgrounds may be added to this list. It appears that appropriately designed school play areas may serve to increase VPA and promote cardiorespiratory fitness.

Physical activity guidelines provide time-related targets for health promoting physical activity, and this study quantified the amount of time that children spent in MVPA and VPA. Before the intervention, children in intervention and control schools engaged in 27 and $30 \mathrm{~min}$ of MVPA per day, respectively, compared to intervention scores of 35 and 25 min of MVPA for intervention and control schools, respectively. Thirty minutes per day is the minimal amount of recommended daily MVPA in young people and primary age children may meet this recommendation during recess alone. Physical activity guidelines also recommend that children should engage in VPA to promote flexibility, strength, and bone health. This investigation demonstrated that multicolored playground markings stimulated a significant increase in VPA. Children in the intervention group engaged in 50\% more VPA after the intervention than children in the control group.

One of the most striking findings of this investigation was the range of individual differences in children's physical activity prior to and following the intervention. Furthermore, random error in VPA was relatively larger than that found in MVPA. These ranges reflect the pattern and tempo of physical

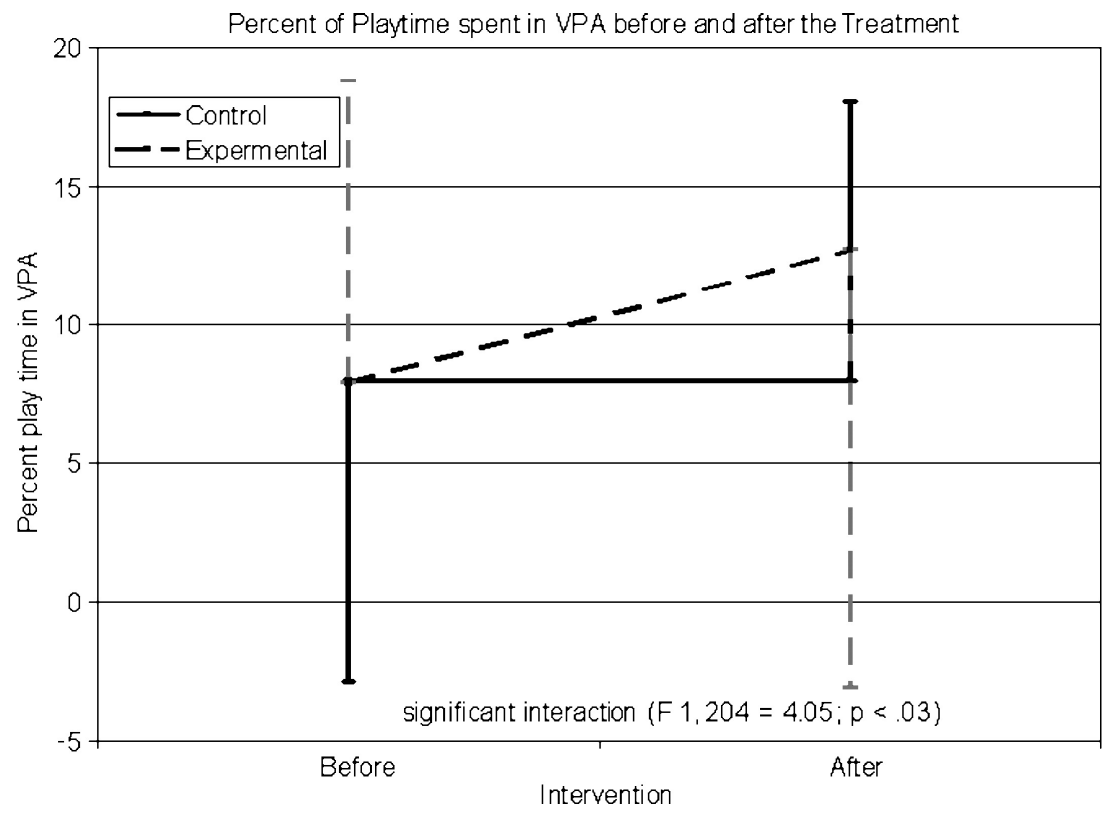

Fig. 2. Control and intervention group's VPA before and after playgrounds were painted. 
activity engagement in school playgrounds and are supported by observational data (Stratton and Motta, 1999).

While recognizing the limitations of quasi-experimental investigations, there are other factors, such as season, social relationships, school tuck shops, ${ }^{1}$ playground equipment, adult prompting, and the school curriculum, that may influence children's playtime physical activity levels besides playground markings.

The principal research tool used to measure physical activity, heart rate telemetry, has particular limitations. Results may differ depending on an individual's emotional state and level of fitness (Rowland, 1997) and the recording interval used (Stratton, 1999b). Furthermore, heart rate telemetry may overestimate energy expenditure (Louie et al., 1999). The results of this investigation should be interpreted with these limitations in mind.

Finally, the increased physical activity levels found here may be attributable to a "novelty effect" which may or may not be sustainable. It is possible that children's enthusiasm for playing on the markings would diminish over time. Re-painting playgrounds may re-ignite enthusiasm for physical activity engagement. Further investigations should attempt to seek ways to address this problem by measuring physical activity over a sustained period after intervention.

In conclusion, this study found that after controlling for body mass and play duration, painting playgrounds with multicolor markings significantly increased children's MVPA and VPA in the short term. If these levels of physical activity could be sustained, then multicolored playgrounds could make a valuable contribution to the achievement of health-related physical activity recommendations for young people. This would allow children to gain short- and long-term health benefits, and to maintain physically active lifestyles into adulthood (Trudeau et al., 1999).

Results also demonstrate that a target of $50 \%$ of MVPA during recess on a daily basis is achievable. These thresholds could provide useful markers for future investigations that aim to judge whether playgrounds stimulate appropriate levels of physical activity.

\section{Acknowledgments}

Health Promotion Department of Welsh Assembly for supporting this project. The children, parents, and teachers from the schools that took part.

\section{References}

Andersen, L.B., Hasselstrom, H., Gronfeldt, V., Hansen, S.E., Karsten, F., 2004. The relationship between physical fitness and clustered risk, and tracking of clustered risk from adolescence to young adulthood: eight years follow-up in the Danish Youth and Sport Study. Int. J. Behav. Nutr. Phys. Act 1,6 .

Armstrong, N., McManus, A., 1994. Children's fitness and physical activity: a challenge for physical activity. Br. J. Phys. Educ. 25, 20-26.

\footnotetext{
${ }^{1}$ School tuck shops sell food snacks during playtime periods.
}

Bailey, D.A., 1994. The role of mechanical loading in the regulation of skeletal development during growth. In: Blimkie, C.J.R., Bar-Or, O. (Eds.), New Horizons in Pediatric Exercise Science. Human Kinetics, Champaign, IL, pp. 97-108.

Biddle, S., Sallis, J., Cavill, N. (Eds.), 1988. Young and Active: Physical Activity Guidelines for Young People in the UK. Health Education Authority, London.

Centers for Disease Control and Prevention, 1997. Guidelines for school and community programs to promote lifelong physical activity among young people. Morb. Mort. Wkly. Rep. 46 (No. RR-6).

Cureton, K.J., Baumgartner, T.A., McManis, B.G., 1991. Adjustment of 1 mile run/walk test scores for skinfold thicknesses in youth. Pediatr. Exerc. Sci. 3, $152-167$.

Durant, R.H., Baranowski, T., Davis, H., Thompson, W.O., Puhl, J., Greaves, K.A., et al., 1992. Reliability and variability of heart rate monitoring in 3 year old, 4 year old, or 5 year old children. Med. Sci. Sports Exerc. 24, $265-271$.

Health Promotion Wales. The health promoting playground project: evaluation findings. Research Summary 1997; Issue 1. Cardiff. UK.

Hovell, M.F., Bursick, J.H., Sharkey, R., McClure, J., 1978. Evaluation of elementary students voluntary physical activity during recess. Res. Q. Exerc. Sport 49, 460-474.

Iverson, D.C., Fielding, J.E., Crow, R.S., Christenson, R.M., 1985. The promotion of physical activity ion the United States population: the status of programmes in medical, worksite, community and school settings. Public Health Rep. 100, 212-224.

Jarman, B., 1984. Underprivileged areas: validation and distribution of scores. BMJ 289, 1587-1592.

Kraft, R.E., 1989. Children at play; behaviour of children at recess. JOPERD $60,21-24$.

Lohman, T.G., Roche, A.F., Martorell, R., 1991. Anthropometric Standardisation Reference Manual (Abridged Edition). Human Kinetics Publishers, Champaign, IL.

Louie, R., Eston, R.G., Rowlands, A.V., Tong, K.K., Ingledew, D.K., Fu, F.H., 1999. Validity of heart rate, pedometry and accelerometry for estimating the energy cost of activity in Hong Kong Chinese boys. Pediatr. Exerc. Sci. 11, $229-239$.

McKenzie, T.L., Sallis, J.F., Elder, J.P., Berry, C.C., Hoy, P.L., Nader, P.R., et al., 1997. Physical activity levels and prompts in young children at recess: a two-year study of a bi-ethnic sample. Res. Q. Exerc. Sport 68, $195-202$.

Pate, R.R., Baranowski, T., Dowda, M., Trost, S.G., 1996. Tracking of physical activity in young children. Med. Sci. Sports Exerc. 28, 92-96.

Payne, V.G., Morrow, J.R., 1993. The effect of physical training on prepubescent $\mathrm{VO}_{2} \mathrm{max} ; \mathrm{a}$ meta-analysis. Res. Q. Exerc. Sport 64, $305-313$.

Ridgers, N.D., Stratton, G., Fairclough, S.J., 2006. Assessing physical activity during recess using accelerometry. Prev. Med. 41, 102-107.

Rowland, T.W., 1997. Limitations of heart rate monitoring in children. Sports Med. 24, 258-272.

Saakslahti, A., Numminen, P., Valimaki, I., 1999. The effects of intervention on children's physical activity during a 3.5 year follow-up study. Proceedings of the 4th Annual Congress of the European College of Sports Science, Rome, Italy.

Sleap, M., Warburton, P., 1992. Physical activity levels of 5-11 year-old children in England, as determined by continuous observation. Res. Q. Exerc. Sport 63, 238-245.

Stratton, G., 1996. Children's heart rates during physical education lessons: a review. Pediatr. Exerc. Sci. 8, 215-233.

Stratton, G., 1999a. A preliminary study of children's physical activity in one urban primary school playground: differences by sex and season. J. Sp. Ped. $5,71-81$.

Stratton, G., 1999b. Limits of agreement between 5 and 60 second heart rate recording intervals during school recess. Pediatr. Exerc. Sci. 11, $253-254$.

Stratton, G., 2000. Promoting children's physical activity in primary school: an intervention study using playground markings. Ergonomics 43, 1538-1546.

Stratton, G., Mota, J., 1999. Girls' physical activity during primary school 
playtime: a validation study using systematic observation and heart rate telemetry. J. Hum. Mov. Stud. 38, 102-121.

Trudeau, F., Laurencelle, L., Tremblay, J., Rajic, M., Shephard, R.J., 1999. Daily primary school physical education: effects on physical activity during adult life. Med. Sci. Sports Exerc. 31, 111-117.
Welk, G.J., 1999. The youth physical activity promotion model: a conceptual bridge between theory and practice. Quest 51, 5-23.

Welsman, J., Armstrong, N., 1997. Physical activity patterns of 5 to 11 year old children. In: Armstrong, N., Kirby, B., Welsman, J. (Eds.), Children and exercise XIX: promoting health and well being, pp. 139-144. 